\title{
The effectiveness of functional task exercise and physical therapy as prevention of functional decline in community dwelling older people with complex health problems
}

Petra C. Siemonsma', Jeanet W. Blom², Hedwig Hofstetter ${ }^{2}$, Ariëtte T. H. van Hespen ${ }^{2}$, Jacobijn Gussekloo ${ }^{3}$, Yvonne M. Drewes ${ }^{3}$ and Nico L. U. van Meeteren ${ }^{1,4,5}$

\begin{abstract}
Background: A physically active lifestyle in older people contributes to the preservation of good health. We assessed the influence of physiotherapy on daily functioning among community dwelling older people (75+) with complex health problems identified with screening, versus usual care. We also compared functional task exercise (FTE), with problems prioritized by older people, trained in the home environment, versus usual preventive physical therapy (PPT).

Methods: Design: FTE and PPT were compared in a randomized controlled trial (RCT). Both interventions were compared with daily functioning in an observational study: control group.

Setting/Participants: Community-dwelling persons aged $\geq 75$ years with daily activity limitations enlisted in 83 general practices $(n=155)$.

Interventions: Both intervention groups (FTE, $n=76$ and PPT, $n=79$ ) received individual, 30 min treatments.

The control group $(n=228)$ did not get any experimental intervention offered.

Measurements: Groningen Activities of Daily Living Restriction Scale (GARS).

Statistical analyses: Linear Mixed Model analysis, correcting for age, sex, baseline scores and clustering by physiotherapist were used to compare the different groups.
\end{abstract}

Results: At baseline, 74\% percent of the intervention trial group was female vs 79\% in the control group. Median ages were 83.9 and 84.7 respectively.

The median baseline GARS-score for the control group was 41.0 (25 and 75 percentile): $35.0 ; 48.0$ ) and 40.0 (25 and 75 percentile: $32.3 ; 46.0)$ for the intervention group (FTE + PPT). The mean change over time was $3.3(2.5 ; 4.1)$ for the control group. Mean difference in change over time between the intervention (FTE + PPT) and the control group was $-2.5(-4.3 ;-0.6)(p=.009)$.

Between FTE and PPT the difference in change was -0.4 (95\% Cl: -2.3; 3.0, $p=0.795)$.

Conclusion: An exercise intervention led by physiotherapists may slow down decline in self-reported daily functioning in older persons with daily activity limitations, identified by pro-active case finding.

Trial registration: Netherlands trial register (NTR2407). Registered 6th of July 2010.

Keywords: Functional training, Exercise, Older people

\footnotetext{
* Correspondence: J.W.Blom@lumc.nl

${ }^{2}$ Department of Public Health and Primary Care (VO-P), Leiden University

Medical Center, Postbox 9600, 2300, RC, Leiden, The Netherlands

Full list of author information is available at the end of the article
}

(c) The Author(s). 2018 Open Access This article is distributed under the terms of the Creative Commons Attribution 4.0 International License (http://creativecommons.org/licenses/by/4.0/), which permits unrestricted use, distribution, and reproduction in any medium, provided you give appropriate credit to the original author(s) and the source, provide a link to the Creative Commons license, and indicate if changes were made. The Creative Commons Public Domain Dedication waiver (http://creativecommons.org/publicdomain/zero/1.0/) applies to the data made available in this article, unless otherwise stated. 


\section{Background}

The consequences of aging include gradually diminished daily functioning [1-4], which may develop into dependency, institutionalization and mortality [5]. In 2013, in the Netherlands, approximately $62 \%$ of people aged $\geq 75$ years had limitations in performing activities of daily life and $38 \%$ had at least one physical disability [6]. Since our populations are aging, these numbers are expected to rise.

However, there is strong evidence that a physically active lifestyle in older people contributes to the preservation of good health [7], and a higher level of physical activity is associated with reduced incidence of disability, more disability-free years [8] and a longer life [9]. Regular physical training was shown to improve daily physical functioning even in frail older people [10-12].

Functional Task Exercise group program (FTE) is an example of an evidence based program that aims at improving daily activities That are most important to the individual older adult $[3,13,14]$. The FTE group program was shown to be more effective for improvement of daily activities than intensive muscle-strengthening training and no training in older people [14].

An example of how cognitive/perceptual/execution aspects are linked in FTE:

Climbing stairs is an eminent functional activity for most elderly people. In contrast to strengthening exercises for the quadriceps, training stair climbing is a task training. Climbing stairs can be made more intensive by increasing the number of stairs or the speed. This will increase the power and stamina. However carrying one or two bags of groceries up the stairs will force a person to adapt the climbing, for example by countering balance disturbances of being unable to use the handrailing. Carrying a basket of laundry will block the view of the stairs and a person is forced to rely more on other perceptual information that usually. Talking or counting will demand attention and therefore influence the performance. Finally, contextual factors will also force a person to adapt their stairclimbing, for example by having to react to other people descending the stairs or by the type of carpet and steepness of the stairs. The aim of functional training is to increase the difficulty in all areas in order to arrive at a very skilled and flexible performance, in this case stair climbing.

We set out to investigate whether FTE applied to community dwelling older people with complex health problems identified by screening, since the vast majority of people aged 50 years and older want to remain in their current residence, also called 'aging in place' [15]. This added value of FTE, in slowing down functional decline, was compared to non-protocolized physical therapy and we studied how these two compare to usual care. In order to help clinicians in deciding whether 1) to pro-actively prescribe physical therapy, and 2) FTE should be preferred over non-protocolized physical therapy.

\section{Methods}

We used two separate study designs: a randomized controlled trial (intervention trial group) and a control group (cohort) embedded in a randomized controlled trial. The addition of the control group was not intended at the start but proved to be necessary to be able to compare the two interventions to usual care.

\section{Intervention trial group \\ Study design}

FTE and PPT were compared in an, assessor blinded, randomized controlled trial (RCT), the intervention trial group' performed from August 2010 to April 2012.

\section{Study population}

The target population, aged $\geq 75$ years, was selected from 24 primary care practices in the Western part of the Netherlands. The general practitioners (GPs) excluded persons admitted to a nursing home, with a life expectancy of less than three months, or who did not speak Dutch or were otherwise considered not eligible to participate, eg suffering from serious psychiatric illness. Additional exclusion criteria were inability to comprehend and follow instructions and current physical therapy treatment. The remaining persons were invited by their GP by mail to complete a screening questionnaire. (Additional file 1: Appendix 1) The screening questionnaire consisted of 21 items, covering four domains of health: functional, somatic (health and illness), mental and social. The questionnaire has been shown to predict functional decline [16]. A positive answer to $\geq 2$ questions in a domain led to a positive score on the domain. The ISCOPE (Integrated Systematic Care for Older PEople)- screening questionnaire (control group) had a question about managing finances instead of the capability to climb stairs. Non-responders were reminded by telephone and were offered assistance to complete the questionnaire.

Respondents with a positive score on the functional domain and at least one other domain were invited for a further screening home-visit, performed by research assistants. The aim of the screening visit was to obtain socio-demographic and baseline data and to verify the following eligibility criteria: a positive score on the functional domain and at least one other domain (somatic, mental, social), not receiving physiotherapy treatment, a score of $>18$ on the Mini Mental State Examination (MMSE) [17], and to check absolute and relative contra-indications for physical exercise according to the Guidelines for Exercise Test Administration' in de 
ACSM Guidelines for Exercise Testing and Prescription [18]. Eligible older people were invited to participate in the randomized intervention study.

\section{Randomization}

Study participants were randomly assigned to the intervention conditions. A random number sequence was generated using the software environment $R$ version 2.14 [19].

\section{Interventions}

Both FTE and PPT consisted of individual treatments (30 min) for a maximum of 18 treatments within three months, and were provided to participants with the aim of preventing age-related functional decline. Therapists for either FTE or PPT were not working in the same practice to avoid contamination. In only one out of 28 practices treated both intervention were provided, but by different physiotherapists. FTE was provided in the participant's home. For more information on FTE: see Additional file 2: Appendix 2. Physiotherapists in the FTE group received extra training for this type of intervention.

The participants in the PPT group were referred to a regular physical therapist. The location of treatment was up to the therapists' professional opinion. No additional training for the physical therapist for PPT was provided. Twenty percent of therapists already had additional training in elderly care, varying from a course in falls prevention to a master in geriatrics. Therapists received an open referral to help this person with their daily functioning. Any exercises therapy and advise was up to the therapists discretion. Treatment was according to protocols of The Royal Dutch Society for Physical Therapy.

\section{Observational study Study design}

The interventions were compared with the natural course of daily functioning in an observational study design among participants of the ISCOPE-study (trial registration NTR1946) [20], the 'control group'. The ISCOPE study is a cluster randomized trial among persons aged $\geq 75$ years from 59 general practices in and around the city of Leiden, who were invited to participate (inclusion period September 2009 to September 2010).

\section{Study population}

To compose the control group with patient characteristics comparable to the intervention groups, participants were selected from 59 primary care practices $(n=12,066$ eligible older people) who participated in the ISCOPE-study. We selected respondents without missing questionnaires at baseline or at twelve months of follow up, and who did not receive an intervention that was part of the ISCOPE study $(n=4133)$. Participants who had a positive score on the functional domain and at least one other domain (somatic, mental, social), did not receive physical therapy, and had a score of $>18$ on the MMSE were selected [21]. Subsequently, frequency matching was used to obtain the same distribution of scores on the number of domains according to the screening questionnaire as in the intervention trial group.

\section{Measurements}

The intervention trial and the control group used the same outcome measures. Assessments of outcomes were taken at baseline (T0) and 12 months after baseline (T1) in the participant's home by independent allied health professionals blinded for group and study (RCT or control group) allocation/origin. For intervention trial participants, information on the total number of treatments and treatment location were collected from the providers of FTE and PPT.

The primary outcome was self-reported functional ability in activities of daily living (ADL). We used the Groningen Activities Restriction Scale (GARS), an 18 item questionnaire that assesses disabilities in competence in ADL, which is validated in the Dutch population [22]. A sum score was calculated ranging from 18 (competent in all ADL activities) to 72 (unable to perform any activity without help), with higher scores indicating more difficulty in performing ADL.

We added the Modified Katz-15 score of independence in ADL [23], a 15 items questionnaire scoring 1 (yes I need help) or 0 (no I don't need help) for each item. The total sum of the items was used, with a higher sum score indicating more problems in carrying out activities in daily living [23, 24]. This questionnaire is internationally well-known and was added to perform a sensitivity analysis.

\section{Sample size calculation}

For the intervention trial the sample size calculation was based on the findings of a previous study [16] indicating that at least 64 participants in each group were needed to achieve $80 \%$ power to detect a medium effect size (Cohen's $d=0.5$ ) with a significance level (alpha) of 0.05 using a two-sided two-sample t-test. Assuming a drop-out of $15 \%$ (post randomization), 75 (= 64/0.85) older people per group had to start with the intervention.

The size of the control group was based on all available persons in the ISCOPE-study control group that met the eligibility criteria. 


\section{Statistical analyses}

All statistical analyses were performed with SPSS version 23. Descriptive data are presented to characterize the study population and treatment characteristics. We used means with standard deviations (SD) for continuous variables that were normally distributed and medians with 25 and 75 percentiles for continuous variables that were not normally distributed. Proportions were used to describe categorical variables. All analyses were performed according to the intention-to-treat principle (i.e., all baseline data and available follow-up data were included). We computed change over time in outcome variables for both outcome measures. A two-sided $\alpha$ of 0.05 was used as significance level.

In the first analysis of the difference in change on the GARS-score, we compared the two groups in the intervention trial with each other. In the second analysis we compared both intervention groups with the control group. We used Linear Mixed Model (LMM) analysis, correcting for age, sex, baseline scores and clustering by physiotherapist. The model contained a variable for time of measurement (baseline and 12 months) and a variable for 'intervention'. In the first analysis, the estimate for time of measurement shows the mean change in score for the PPT-group, and the estimate for intervention shows the difference in change in score between the PPT and FTE (extra mean change in FTE). In the second analysis, the estimate for time of measurement shows the mean change in score for the control group, and the estimate for intervention shows the difference in change in score (extra mean change in PPT + FTE) between the control group and the intervention trial group (PPT + FTE). We did the same for the sensitivity analysis of the change in modified Katz-15 score. Missing data were accounted for by the statistical techniques used (LMM) [25].

\section{Results}

Inclusion of participants

Randomized controlled trial

For the FTE and PPT-group 5529 older persons were eligible to participate in the screening. After screening, 400 respondents were eligible to be visited, of which 286 participants were visited, and 114 were not approached and invited within the timeframe of the study due to lack of time. Out of these 286 visited persons 155 agreed to participate in the RCT and signed informed consent, i.e. $54 \%(155 / 286)$ of those invited to participate in the RCT did so (Fig. 1).

Five participants died in each intervention trial group during 12 months, i.e. $6.6 \%$ in the FTE and $6.3 \%$ in the PPT group. The total drop-out of the trial at 12 months was $35.5 \%$ for FTE $(n=27)$ and $25.3 \%$ for PPT $(n=20)$ $(p=0.167)$ (Fig. 1).
The average number of participants per physiotherapist was 5 (range 0-12).

\section{Control group}

In the ISCOPE-study 11,476 persons were eligible to participate in the screening. For the ISCOPE-control group 4133 participated in the screening. Of these, 410 participants were eligible for this analysis. After weighing for distribution of the number of domains according to the screening questionnaire we included 228 control subjects (Fig. 1).

\section{Baseline characteristics}

Table 1 presents the characteristics of both intervention trial groups and the control group.

\section{Intensity of interventions}

The number of treatments was on average 11 in FTE and 12 in PPT treatments per person. The treatment setting for FTE was prescribed to be the participant's home for all participants, whereas $80 \%$ of the PPT clients also received treatment at home.

\section{Effectiveness in randomized controlled trial}

The mean change over time in the PPT-group for GARS-score was 2.6 points $(95 \%$ CI: $1.3 ; 3.8)$ ( $p$-value $<0.001)$ and the mean change over time in modified Katz-15-score was 0.1 points $(95 \% \mathrm{CI}$; -0.2 ; 0.5) (p-value 0.509), both indicating a 6.5\% (baseline median score of 4 (25 and 75 percentile $34 ; 46)$ ) and $2.0 \%$ (baseline median score of 5 (25 and 75 percentile 3; 7)) deterioration in self-reported performance in ADL. No statistically significant different results were observed between the FTE and PPT groups in mean change of either outcome measure after 12 months (Table 2).

\section{Effectiveness in observational study}

The control group changed significantly in both GARS and modified Katz-15 scores over time (3.3 (95\% CI: 2.5; 4.1 ) and 0.7 (95\% CI: $0.4 ; 0.9)$ respectively), indicating that this group deteriorated $8.0-14 \%$ during the 12 month follow-up (with a baseline GARS-score of 41 (25 and 75 percentile $35 ; 48$ ) and a baseline modified Katz- 15 score of 5 (25 and 75 percentile 4; 7)). Comparison of the change in scores of the control group to those of the two intervention trial groups showed that the deterioration in the intervention trial groups (FTE + PPT) was significantly less on both GARS and modified Katz-15 scores, i.e. the difference in change of scores was $-2.5(95 \%$ CI $-4.3 ;-0.6, p$-value 0.009$)$ and -0.8 (95\% CI -1.4;-0.3, p-value 0.002), respectively (Table 3). 


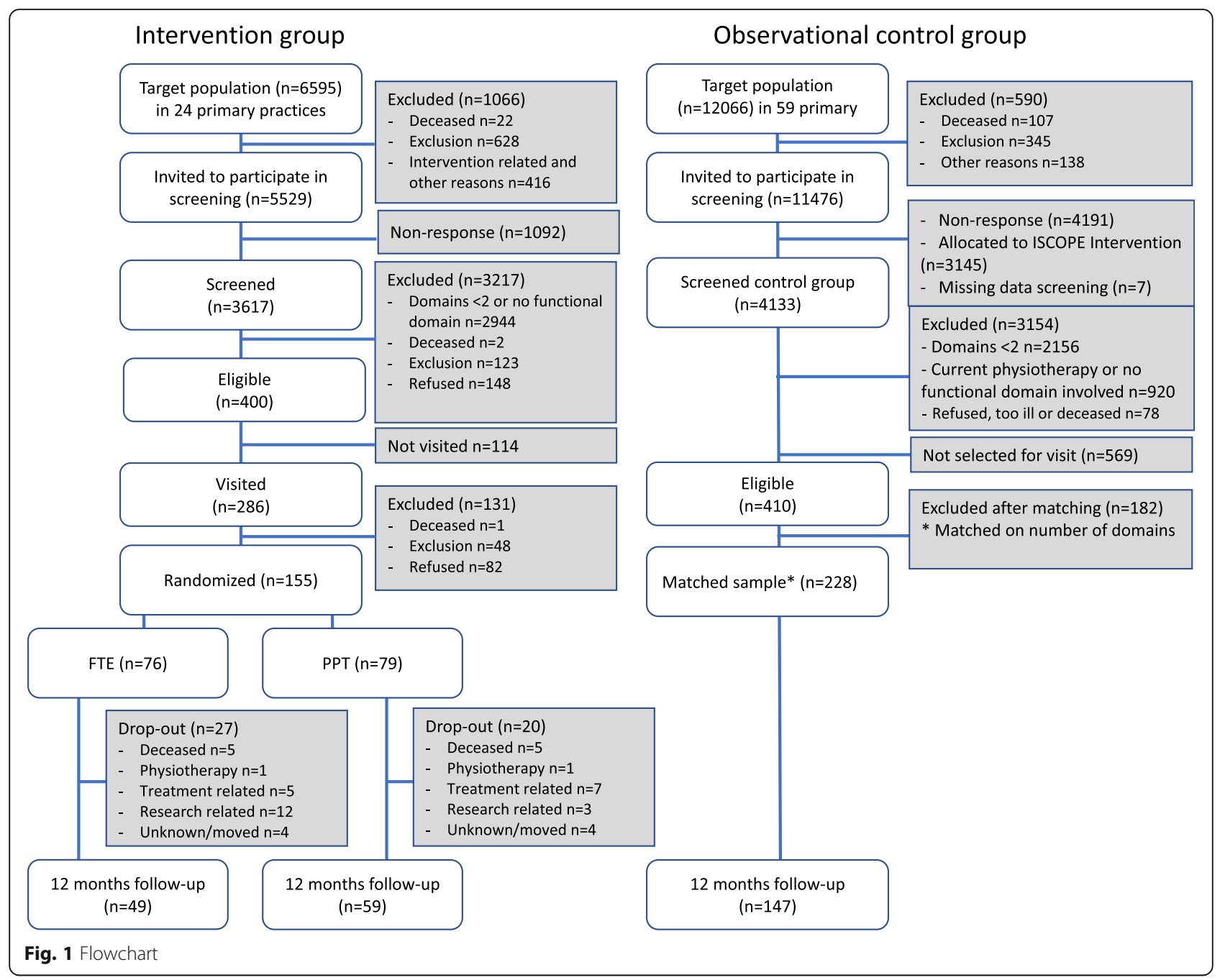

Table 1 Baseline characteristics in the intervention trial groups (PPT and FTE) and the control group

\begin{tabular}{|c|c|c|c|c|}
\hline & Preventive physio therapy & Functional task exercise & Control $^{\mathrm{a}}$ & $\begin{array}{l}P \text {-value control vs } \\
\text { interventions groups }\end{array}$ \\
\hline $\bar{N}$ & 79 & 76 & 228 & \\
\hline Sex ( $n, \%$ female) & $59(75)$ & $55(72)$ & $179(79)$ & 0.761 \\
\hline Age (median (25 and 75 percentile) & $83.9(80.2 ; 86.4)$ & $84.0(79.4 ; 88.7)$ & $84.7(80.5 ; 89.5)$ & 0.769 \\
\hline Number of problem domains $\geq 3$ ( $n(\%))$ & $58(73)$ & $53(70)$ & $164(72)$ & 0.946 \\
\hline $\begin{array}{l}\text { Positive score somatic domain }(n(\%)) \\
\text { Mental domain }(n(\%)) \\
\text { Social domain }(n(\%))\end{array}$ & $\begin{array}{l}69(87) \\
56(71) \\
46(58)\end{array}$ & $\begin{array}{l}67(88) \\
53(70) \\
29(38)\end{array}$ & $\begin{array}{l}204(90) \\
155(68) \\
108(48)\end{array}$ & 0.598 \\
\hline MMSE (median (25 and 75 percentile)) & $28(26 ; 29)$ & $28(26 ; 29)$ & $27(25 ; 29)$ & 0.053 \\
\hline GARS (median (25 and 75 percentile)) & $40(34 ; 46)$ & $40(33 ; 46)$ & $41(35 ; 48)$ & 0.308 \\
\hline Modified Katz-15 (median ( 25 and 75 percentile)) & $5(3 ; 7)$ & $5(3 ; 6)$ & $5(3 ; 7)$ & 0.148 \\
\hline
\end{tabular}

${ }^{a}$ Matched with randomized intervention group for number of problem domains

GARS = Groningen Activity Restriction Scale (higher scores indicate more disability), Modified Katz-15 = Katz Index of independence in ADL (higher sum scores indicate more problems in carrying out activities in daily living)

${ }^{\mathrm{b}} \mathrm{Chi}$-square test for dichotomous variables and Kruskall Wallis test for continuous variables 
Table 2 Daily functioning in the intention-to-treat analysis comparing PPT and FTE adjusted for age at screening, sex, baseline daily functioning and clustering by physiotherapist

\begin{tabular}{|c|c|c|c|c|}
\hline & $\begin{array}{l}\text { Mean change in 1-year follow-up } \\
\text { for PPT group }(n=79)\end{array}$ & $P$-value & $\begin{array}{l}\text { Extra mean change in FTE group } \\
\text { compared to PPT group }(n=76)\end{array}$ & $P$-value \\
\hline GARS total score $(95 \% \mathrm{Cl})$ & $2.6(1.3 ; 3.8)$ & $<0.001$ & $-0.4(-2.3 ; 3.0)$ & 0.795 \\
\hline Modified Katz-15-score (95\% Cl) & $0.1(-0.2 ; 0.5)$ & 0.509 & $-0.4(-1.1 ; 0.4)$ & 0.339 \\
\hline
\end{tabular}

\section{Discussion}

In this study we found that daily functioning deteriorated slightly, in community-dwelling older persons identified with complex problems, in both FTE and PPT group, but the change over one year did not differ significantly between the two groups. However, this study gives an indication that an exercise intervention led by a physiotherapist (FTE or PPT), might reduce deterioration in daily functioning significantly in comparison to the control group, which received no physiotherapy intervention.

It could be that the treatment ingredients in the PPT-group did not differ as much from the treatment in the FTE-group as had been expected. In the PPT group $80 \%$ of treatments were provided in the participants' home which was unexpected. The number of intervention sessions differed by one session on average per person between the two intervention groups. We don't expect a negative effect on the outcome from this small difference.

\section{Comparison to other studies}

Daily physical functioning declined in both intervention trial groups and control group during the one year follow-up. This is in accordance with literature, in which there is consensus about the fact that older persons' health and physical functioning decline with age [3]. An earlier study showed a decline of 3.5 points on the GARS over 1 year in older people of 75 years and older with problems on 3 or more domains on the ISCOPE-questionnaire [20]. Our results suggest a two-third less steep functional decline in both FTE and PPT over one year time span, compared to the control group. This is in agreement with several studies indicating that structured exercise and/or an active lifestyle has a positive impact on older persons with complex health problems $[9,11,26-30]$.
The interventions (FTE and PPT) were found to be equally effective, this is in contrast with previous reviews $[26,27]$ and with the hypothesis we had at the start of the study. However, the findings are in line with two current meta-analyses which state that no definite conclusions on the most effective type of physical therapy can be drawn [28-30].

\section{Strengths and weaknesses of the study}

The systematic recruitment through active case-finding of participants from a large source population representative of community dwelling older people adds to the generalizability of the results. Daily functioning was measured with validated questionnaires by trained allied health professionals during home visits. This increased the reliability and the completeness of the measurements.

A weakness is the fact that only the two intervention arms were randomized for exercise therapy. In spite of matching on complexity of problems there could still be selection bias left due to different eligibility criteria in the intervention groups and the control group: participants in the intervention trial groups (FTE and PPT) could still be more motivated to exercise than participants in the control group because of their active choice to participate. Another weakness is the fact that there was a larger drop out than expected in both intervention groups. In the FTE group more people dropped out because of research related reasons, such as too many questionnaires to fill in. Other reasons were similar. As both groups underwent the same research related procedures we have no explanation for this.

\section{Implications for clinicians and policy makers}

We found that FTE applied to community dwelling older people with complex health problems identified by screening, has no added value compared to non-protocolized physical therapy to slow down

Table 3 Daily functioning in the intention-to-treat analysis comparing the control group and PTT+ FTE, adjusted for age at screening, sex and baseline daily functioning

\begin{tabular}{lllll}
\hline & $\begin{array}{l}\text { Mean change in 1-year follow-up } \\
\text { for control group }(n=228)\end{array}$ & $\begin{array}{l}P \text {-value } \\
\text { GARS total score }(95 \% \mathrm{Cl})\end{array}$ & $\begin{array}{l}\text { Extra mean change in combined PTT+FTE } \\
\text { group compared to control group }(n=155)\end{array}$ & $\begin{array}{c}P \text {-value } \\
\text { Modified Katz-15-score }(95 \% \mathrm{Cl})\end{array}$ \\
\hline
\end{tabular}

GARS = Groningen Activity Restriction Scale (higher scores indicate more disability), Modified Katz-15= Katz Index of independence in ADL (higher sum scores indicate more problems in carrying out activities in daily living) 
functional decline. However, compared to usual care a strategy of exercise therapy for this group of older people might have a beneficial effect on daily function. This study shows that a proactive way of working, i.e. offering an intervention to older people identified by screening, might be beneficial. This offers options for clinicians to be more pro-active in offering exercise therapy to older people. However, the low uptake of the intervention remains a concern, as many older people have to be screened and visited in order to identify relatively few participants for the intervention.

\section{Future research}

So far, it is unclear which components of exercise therapy are effective in maintaining or improving ADL-function of older people. Generally, it seems exercise as such is beneficial. It seems a logical hypothesis that preventive personalized exercise exercise at home is beneficial for functioning in older people. However, the question if therapy is more effective if given at home also still remains open.

\section{Additional files}

Additional file 1: Appendix 1. ISCOPE-screening questionnaire. (DOCX $14 \mathrm{~kb}$ )

Additional file 2: Appendix 2. Description of FTE-therapy. (DOCX $14 \mathrm{~kb}$ )

\section{Abbreviations}

ADL: Activities of Daily Living; FTE: Functional Task Exercise; GARS: Groningen Activities of Daily Living Restriction Scale; GP: General Practitioner; ISCOPE: Integrated Systematic Care for Older PEople; LMM: Linear Mixed Model; MMSE: Mini Mental State Examination; PPT: Preventive Physical Therapy; RCT: Randomized Controlled Trial; SPSS: Statistical Package for the Social Sciences

\section{Acknowledgements}

We thank the participants in the study, the participating health care provides; Mariëlle Jans and Paul De Vreede for their contributions the early phases of the study; TNO colleagues contributing to the data collection and writing process: Ineke van Kempen, Janine Stubbe and Sandra BauschGoldbohm; LUMC colleaques for advice: Elske van den Akker-van Marle. Also the advisory board with experts from general practice, physiotherapy and elderly care physicians, as well as the older people from the client board of Zorgbelang South Holland North.

\section{Funding}

This study was funded by ZonMw, the Netherlands, Organization for Health Research and Development: ZonMw 60-6190-98-215, as part of the Netherlands Care for the Elderly Program. Open access of this publication was financed by the Netherlands Organization for Scientific Research (NWO). The sponsor had no role in the design and conduct of the study; collection, management, analysis, and interpretation of the data; and preparation, review, or approval of the manuscript.

\section{Availability of data and materials}

All raw data are available upon request at Mr. D. Kloet, research manager at TNO Healthy Living, Leiden, Schipholweg 77-89, 2316 ZL Leiden, The Netherlands. Telephone + 31623710472 .

\section{Authors' contributions}

Guarantor: NLUVM had full access to all of the data in the study and takes responsibility for the integrity of the data and the accuracy of the data analysis. Study concept and design: ATHVH, JG, NLUVM. Acquisition of data: ATHVH, YMD, PCS. Analysis and interpretation of data: PCS, JWB, HH, JG, NLUVM. YMD. Drafting of the manuscript: PCS, JWB, JG, NLUVM. Critical revision of the manuscript for important intellectual content: PCS, JWB, HH, JG, NLUVM, YMD. Obtained funding: JWB, JG and NLUVM. All authors agree to be accountable for all aspects of the work. All authors read and approved the final manuscript.

\section{Ethics approval and consent to participate}

The medical ethical committee of Leiden University Medical Center approved the study in 2010 (P09.175). Participants provided signed informed consent forms.

\section{Consent for publication}

Not applicable.

\section{Competing interests}

The authors declare that they have no competing interests.

\section{Publisher's Note}

Springer Nature remains neutral with regard to jurisdictional claims in published maps and institutional affiliations.

\section{Author details}

${ }^{1}$ TNO Healthy Living, Leiden, Schipholweg 77-89, 2316, ZL, Leiden, The Netherlands. ${ }^{2}$ Department of Public Health and Primary Care (VO-P), Leiden University Medical Center, Postbox 9600, 2300, RC, Leiden, The Netherlands. ${ }^{3}$ Department of Gerontology and Geriatrics, Leiden University Medical Center, Leiden, The Netherlands. ${ }^{4}$ Topsector Life Sciences and Health (Health Holland), The Haque, the Netherlands. ${ }^{5}$ CAPHRI, Maastricht University, Maastricht, the Netherlands.

Received: 30 May 2017 Accepted: 9 July 2018

Published online: 17 July 2018

\section{References}

1. LaCroix AZ, Guralnik JM, Berkman LF, et al. Maintaining mobility in late life. 2. Smoking, alcohol consumption, physical activity, and body mass index. Am J Epidemiol. 1993:137:858-69.

2. Porter MM, Vandervoort AA, Lexell J. Aging of human muscle: structure, function and adaptability. Scand J Med Sci Sports. 1995;5:129-42.

3. Diehr PH, Thielke SM, Newman AB, et al. Decline in health for older adults: five-year change in 13 key measures of standardized health. J Gerontol A Biol Sci Med Sci. 2013 Sep;68(9):1059-67.

4. van Houwelingen AH, Cameron ID, Gussekloo J, et al. Disability transitions in the oldest old in the general population. The Leiden 85-plus study. Age. 2014 Feb;36(1):483-93.

5. Lord SR, Ward JA, Williams $P$, et al. The effect of a 12-month exercise trial on balance, strength, and falls in older women: a randomized controlled trial. J Am Geriatr Soc. 1995:43:1198-206.

6. Statistics Netherlands CBS. Ministry of Health, welfare and sports. Vademecum of health statistics of the Netherlands 1997. 'S-Gravenhage'. Netherlands: SDU; 1997. p. 130-1.

7. Nelson ME, Rejeski WJ, Blair SN, et al. Physical activity and public health in older adults: recommendation from the American College of Sports Medicine and the American Heart Association. Med Sci Sports Exerc 2007:39:1435-45.

8. Nusselder WJ, Looman CWN, Franco OH, et al. The relation between nonoccupational physical activity and years lived with and without disability. J Epidemiol Community Health. 2008;62:823-8.

9. Rizzuto D, Orsini N, Qiu C, et al. Lifestyle, social factors,and survival after age 75: population based study. BMJ. 2012 Aug 29;345:e5568.

10. Chin A, Paw MJM, van Uffelen JGZ, Riphagen I, et al. The functional effects of physical exercise training in frail older people. A systematic review Sports Med. 2008:38:781-93.

11. Cesari M, Vellas B, Hsu FC, et al. LIFE study group. A physical activity intervention to treat the frailty syndrome in older persons-results from the LIFE-P study. J Gerontol A Biol Sci Med Sci. 2015 Feb;70(2):216-22. 
12. de Vries NM, van Ravensberg CD, Hobbelen JSM, Olde Rikkert MGM, Staal JB, Nijhuis-van der Sanden MWG. Effects of physical exercise therapy on mobility, physical functioning, physical activity and quality of life in community-dwelling older adults with impaired mobility, physical disability and/or multi-morbidity: a meta-analysis. Ageing Res Rev. 2012;11(1):136-49.

13. De Vreede PL, Samson MM, van Meeteren NL, et al. Functional tasks versus resistance exercise to improve daily function in older women: a feasibility study. Arch Phys Med Rehabil. 2004:85:1952-61.

14. De Vreede PL, Samson MM, van Meeteren NL, et al. Functional-task exercise versus resistance strength exercise to improve daily function in older women: a randomized controlled trial. J Am Geriatr Soc. 2005;53:2-10.

15. Kochera A, Straight A, Guterbock T. on behalf of the AARP. Beyond 50.05 a report to the nation on livable communities: creating environments for successful aging. 2005. http://assets.aarp.org/rgcenter/il/beyond_50_ communities.pdf.

16. van Houwelingen AH, den Elzen WP, le Cessie $\mathrm{S}$, et al. Consequences of interaction of functional, somatic, mental and social problems in community-dwelling older people. PLoS One. 2015 Apr 21;10(4):e0121013.

17. Folstein MF, Folstein SE, McHugh PR. Mini mental state'. A practical method for grading the cognitive state of patients for the clinician. J Psychiatr Res. 1975;12:189-98.

18. Pescatello S, Arena R, Riebe D, Thompson PD. ACSM's guidelines for exercise testing and prescription. Philadelphia: Wolters Kluwer/Lippincott Williams \& Wilkins Health; 2014.

19. Team, R. Core. R: A language and environment for statistical computing. [homepage on the internet]. Vienna: R Foundation for Statistical Computing [cited 2013].

20. Blom JW, Den Elzen WPJ, Van Houwelingen AH, et al. Effectiveness and cost-effectiveness of a proactive, goal-oriented, integrated care model in general practice for older people. A cluster randomized controlled trial: integrated systematic care for older people - the ISCOPE study. Age and Aging. 2016;45(1):30-41.

21. Tombaugh TN, Mclntyre NJ. The mini-mental state examination: a comprehensive review. J Am Geriatr Soc. 1992 Sep;40(9):922-35.

22. Kempen Gl, Miedema I, Ormel J, et al. The assessment of disability with the Groningen activity restriction scale. Conceptual framework and psychometric properties. Soc Sci Med. 1996:43:1601-10

23. Laan W, Zuithoff NP, Drubbel I, et al. Validity and reliability of the Katz-15 scale to measure unfavorable health outcomes in community-dwelling older people. J Nutr Health Aging. 2014 Nov;18(9):848-54.

24. Buurman BM, van Munster BC, Korevaar JC, et al. Variability in measuring (instrumental) activities of daily living functioning and functional decline in hospitalized older medical patients: a systematic review. J Clin Epidemiol. 2011:64:619-27.

25. Twisk J, de Boer M, de Vente W, et al. Multiple imputation of missing values was not necessary before performing a longitudinal mixed-model analysis. J Clin Epidemiol. 2013 Sep;66:1022-8.

26. Chin a Paw M, van Uffelen JGZ, Riphageven I, et al. The functional effects of physical exercise training in frail older people; a systematic review. Sports Med. 38:781-93.

27. Theou O, Stathokostas L, Roland KP, et al. The effectiveness of exercise interventions for the management of frailty: a systematic review. J Aging Res. 2011;569194

28. Giné-Garriga M, Roqué-Fíguls M, Coll-Planas L, et al. Physical exercise interventions for improving performance-based measures of physical function in community-dwelling, frail older adults: a systematic review and meta-analysis. Arch Phys Med Rehabil. 2014 Apr;95(4):753-769.e3.

29. de Labra C, Guimaraes-Pinheiro C, Maseda A, et al. Effects of physical exercise interventions in frail older adults: a systematic review of randomized controlled trials. BMC Geriatr. 2015 Dec 2;15:154.

30. Silva RB, Aldoradin-Cabeza H, Eslick GD, et al. The effect of physical exercise on frail older persons: a systematic review. J Frailty Aging. 2017;6(2):91-6.

\section{Ready to submit your research? Choose BMC and benefit from:}

- fast, convenient online submission

- thorough peer review by experienced researchers in your field

- rapid publication on acceptance

- support for research data, including large and complex data types

- gold Open Access which fosters wider collaboration and increased citations

- maximum visibility for your research: over $100 \mathrm{M}$ website views per year

At BMC, research is always in progress.

Learn more biomedcentral.com/submissions 